\title{
Comparison of CCM3 Simulations Using Two Climatological Ozone Data Sets
}

\author{
J.S. Boyle
}

February 1997

This is an informal report intended primarily for internal or limited external distribution. The opinions and conclusions stated are those of the author and may or may not be those of the Laboratory.

Work performed under the auspices of the U.S. Department of Energy by the Lawrence Livermore National Laboratory under Contract W-7405-ENG-48. 


\section{DISCLAIMER}

This document was prepared as an account of work sponsored by an agency of the United States Government. Neither the United States Government nor the University of California nor any of their employees, makes any warranty, express or implied, or assumes any legal liability or responsibility for the accuracy, completeness, or usefulness of any information, apparatus, product, or process disclosed, or represents that its use would not infringe privately owned rights. Reference herein to any specific commercial product, process, or service by trade name, trademark, manufacturer, or otherwise, does not necessarily constitute or imply its endorsement, recommendation, or favoring by the United States Government or the University of California. The views and opinions of authors expressed herein do not necessarily state or reflect those of the United States Government or the University of California, and shall not be used for advertising or product endorsement purposes.

This report has been reproduced directly from the best available copy.

Available to DOE and DOE contractors from the Office of Scientific and Technical Information

P.O. Box 62, Oak Ridge, TN 37831

Prices available from (615) 576-8401, FTS 626-8401

Available to the public from the

National Technical Information Service

U.S. Department of Commerce

5285 Port Royal Rd.,

Springfield, VA 22161 


\title{
Comparison of CCM3 Simulations Using Two Climatological Ozone Data Sets
}

\author{
James S. Boyle \\ Program for Climate Model Diagnosis and Intercomparison \\ Lawrence Livermore National Laboratory \\ Livermore, CA USA
}

February 1997 


\begin{abstract}
A comparison of two six year simulations with the CCM3 using different monthly mean, zonally symmetric ozone climatologies is presented.Each run was identical except for the ozone specification. The climatological SSTs supplied with CCM3 were cycled for the extent of the simulation.

The ozone data sets used were the data distributed with the CCM3 code and that compiled at SUNY Albany. The SUNYA data set reflects contemporary ozone measurements extensively using remote sensed data. The CCM3 data were produced from measurements prior to 1974. A brief comparison of the two ozone climatologies is presented.

The monthly mean difference fields were computed for the six years of the simulations. A t-test was applied to the monthly mean difference to judge if the changes between the integrations were significant.

The significant changes in temperature were for the most part confined to the levels above $200 \mathrm{hPa}$. In the zonal mean the patterns of differences were largely consistent with regions of the ozone variations. Deeper tropospheric penetration of temperature differences occurred in October near the South Pole in the region of the "ozone hole". The significant temperature changes at the lowest model level ( 992 $\mathrm{hPa}$ ) were confined to very small areas.

The $200 \mathrm{hPa}$ zonal wind differences demonstrated that the stationary wave structure was evidently altered by the ozone differences. Although the ozone specifications were zonally symmetric, the zonal wind differences were zonally asymmetric at $200 \mathrm{hPa}$.
\end{abstract}




\section{Introduction}

This report describes differences found in integrations of the NCAR CCM3 using two zonally symmetric climatological monthly mean ozone data sets. One ozone data set is that supplied with the distribution of the CCM3. The other is a more recent compilation put together by workers at SUNY Albany. Wang et al. (1995), hereafter W95 report on a very similar set of simulations using the GENESIS model. The W95 experiment used an atmospheric model with a $\mathrm{R} 15 / \mathrm{L} 12$ configuration coupled to a mixed layer ocean with prescribed heat transport. W95 used a longitudinally varying version of the SUNYA ozone set rather than zonally averaged values as was done here. The procedure used was to calculate the ozone path length distribution at each radiation step of the model at each grid point given the current surface pressure, the time dependent climatological vertical distribution with the constraint that the column integrated values were equal to the TOMS climatology. W95 reported on the last ten years of two twenty year integrations with each ozone set. For the surface temperature W95 found that the global mean differences were small but the regional differences could be substantial especially at high and middle latitudes of the Northern Hemisphere during winter. They noted considerably larger effects in the upper troposphere and lower stratosphere. W95 concluded that the changes induced by the ozone differences indicated that the observed ozone variations in the last few decades may have played a role in affecting the climate.

Molnar et al. (1994) using a two dimensional radiative-convective model indicate that the ozone forcing of climate variations is rather sensitive to the vertical profile of the ozone depletions. It would be useful to carry out experiments using different vertical profiles for contemporary ozone observations. The specification of the ozone profile is still one of the larger uncertainties in the analyses of ozone.

A prime motivation for this study is that the zonally averaged SUNYA ozone climatology have been recommended for use in the AMIP II experiment. It was felt that the impact of this new data set should be described for at least one GCM. In the next section the two ozone data sets used in this study will be briefly described and compared. The following section will describe the experimental details and the final section will present the results and conclusions. 


\section{Ozone data sets}

a. SUNYA ozone data

The SUNYA data set is described by Wang et al. (1995). The total column values for these data are based on the TOMS (Total Ozone Mapping Spectrometer) measurements. These are provided as monthly-mean values from November 1978 to January 1992 on a $1.25 \times 2$, longitude, latitude grid. The missing values at high latitudes during the winter were filled with available ozonesonde observations near the poles. The stratospheric vertical distribution is based on the data from the SAGE II (Stratospheric Aerosol and Gas Experiment) which provides data up to $60 \mathrm{~km}$ at $1 \mathrm{~km}$ resolution from October 1984 to November 1989 . Above $60 \mathrm{~km}$ a single mean value at 100 $\mathrm{km}$ taken from McClatchey et al. 1992 is used to calculate the mixing ratios assuming a linear relationship between the logarithm of the ozone value and pressure. Troposphere data was taken from Logan(1985) and Spivakovsky et al. (1990), which have values at $1000,900,850,800,700,500,300,200,150$, and $70 \mathrm{mb}$ at a 10 to 20 degree latitude resolution. Linear interpolation is used to calculate the values between 12 and $17 \mathrm{~km}$.

The data used here are in the form of the 12 month climatological, zonal means. The data are available at 59 levels, with the bulk of the resolution being in the upper atmosphere.

The approximate levels in $\mathrm{hPa}$ are $0.284191,0.32535,0.371936,0.424615$, $0.484153,0.551432,0.62749,0.713542,0.811039,0.921699,1.04757,1.19108$, $1.35511, \quad 1.54305,1.75891,2.00739,2.29403,2.62529,3.00884,3.45369,3.9705$, $4.5719,5.27278,6.09073,7.04636,8.16371,9.47075,11,12.7894,14.8832,17.3342$, 20.2039, 23.5659, 27.5066, 32.1283, 37.5509, 43.915, 51.384, 60.1483, 70.4289, 82.483, 96.6096, 113.155, 132.514, 155.122, 181.445, 211.947, 247.079, 287.273, $332.956,384.573,442.61,507.601,580.132,660.837,750.393,849.521,958.981$, 1003.69 .

\section{b. CCM2/CCM3 ozone data}

For a representative older climatology the two dimensional (latitude, pressure) data provided with the CCM2 (Community Climate Model 2, NCAR) release and the initial release of the CCM3 was selected. These data are derived from values in a climatology compiled by Dutsch (1978). They represent data available up to 1974. 


\section{c. Comparison}

Wang et al. (1995) compared the CCM2 data set to the SUNYA product and found the vertically integrated values to be close. The largest absolute differences they cited were large differences in regions of ozone depletion near the poles. There were large relative differences in the equatorial troposphere and lower stratosphere.

Figure 1 presents the cross section values of the two ozone sets for the month of October. It can be seen that the two data sets are qualitatively similar. The most easily seen difference is the larger values of SUNYA data at the topmost levels centered on the equator. Figure 1 is useful for showing some aspects of the differences but for the purpose here the pertinent comparison should be carried out on the CCM3 vertical grid since it is these data that impact the physics of the model. The model vertical coordinate is a hybrid sigma/pressure system. The levels are nominally at the 18 pressures levels of $992.53,970.45,929.28,866.41,786.51,695.17,598.25,501.28,408.96$, $324.85,251.24,189.19,138.71,99.04,63.95,32.56,13.07,4.81 \mathrm{hPa}$. Much of the information in the SUNYA data 59 levels is lost in going to the 18 level CCM3. The topmost 21 levels of the SUNYA data are not used at all.

Figure 2 presents the difference, SUNYA - CCM3, in the two data sets on the model vertical grid for the months of January, March, July and October. Note that the vertical extent of these figures is only up to $\sim 5 \mathrm{hPa}$. There is a consistent and considerable underestimate of the values in the Tropical (30N-30S) stratosphere by the CCM3 data compared to the SUNYA. The CCM3 values tend to be overestimates near the poles, with a large discrepancy occurring in October near the South Pole. This is a reflection of the contemporary "ozone hole" in the austral spring.

The difference fields emphasize the upper levels since the ozone values are so much larger in these regions. Figure 3 presents the ratio of the SUNYA data to the CCM3, SUNYA/CCM3. These are large in the mid and lower troposphere where the percentage changes are prominent. There are also local maxima near the poles at about 300 to $400 \mathrm{hPa}$, especially during the cool seasons. This might be a reflection of difficulties in defining the tropopause between the two data sets. The large gradients in ozone implicitly define a tropopause and this definition might well be inconsistent with the optimal model climatology as well as other ozone sets. 


\section{Experiment description and calculations}

The data used for the model initial conditions were the September data supplied in the CCM3 distribution. The sea surface temperatures used were the 12 month climatology of the CCM3 distribution which were cycled through for the entire extent of the simulations. For each ozone data set the model was run for 17 months from the September initial conditions and the subsequent six years of integration were taken as the data for this study. The two runs were identical with the exception of the ozone specification. The model output was archived in the form of monthly means.

To gain some idea of the significance of the differences seen in the two runs a simple t-test statistic was computed. The test was carried out for each month of the year individually, so there were six samples for each month from which the means and unbiased estimates of variance were obtained. W95 used 10 years of data, however, since we are specifying the SST which do not vary from year to year, the statistics used here can be on a smaller data set of 6 years.

\section{Results}

Figure 4 presents the zonal mean temperature difference between the model simulations for the months of January, March, July and October. The light and dark shading on the plots are the regions judged to be significantly different based on the local t-test at the $5 \%$ and $1 \%$ levels, respectively. For such a small sample size (6), it is prudent to only consider regions where the significance level exceeds $1 \%$.

The temperature differences are consistent with the ozone differences in Figs. 2 and the seasonal changes of the insolation. The temperatures differences evince a dipole of positive values at the uppermost layers and negative values just below. The impact of the "ozone hole" is also evident in near the South Pole in the October plot. An analogous feature in the boreal spring near the North Pole shows large differences but apparently there is enough variance such that these values cannot be ruled significant. The larger differences are almost entirely confined to above $200 \mathrm{hPa}$ although there are some scattered values in the troposphere.

Figure 5 presents the same figures as Fig. 4, except for the zonal wind. By the thermal wind relation, these plots give a picture of the vertically integrated, meridional temperature gradient. Again the bulk of the differences are confined to the upper 
most layers. An exception occurs in January in the Northern Hemisphere. Around $30 \mathrm{~N}$ there are significant values down to $400 \mathrm{hPa}$, the dipole structure of the differences indicates a shift in the location of the jet. The lower variance on the equatorward side of the jet allows for the values in these regions to be judged significant.

These plots of the zonally averaged fields are consistent with what might be expected given the differences in the prescribed ozone sets. Since the prescribed sets have no longitudinal variation, it might be expected that the zonally averaged data would be adequate to describe the nature of the differences in the two simulations. This assumption is not entirely valid as will be seen in the following section.

Figure 6 presents the differences in the $100 \mathrm{hPa}$ temperatures for January, March, July and October. There is substantial zonal variation in the differences, especially in the Northern winter and spring. W95 also noted a zonal asymmetry in their difference fields using a longitudinally varying ozone climatology.

Figure 7 presents the differences in the zonal mean wind between the two simulations for at $200 \mathrm{hPa}$ for January, March, July and October. Also depicted are the ttest values. As in the temperature fields, the zonal wind posses some zonal structure. Figure 7a, January, indicates a significant alteration of the stationary waves. There is a systematic variation at the entrance and exit regions of the principal $200 \mathrm{hPa}$ jet maxima over East Asian and North America. The zonal wind differences in the Southern hemisphere show a larger asymmetry than did the $100 \mathrm{hPa}$ temperatures. Figure 8 is a cross section taken at $150 \mathrm{~W}$ from pole to pole for the zonal wind differences during January. This is the longitude of the largest differences seen in Fig.7a. The point of the figure is to illustrate that the differences can extend throughout the depth of the atmosphere, although they generally are small at the surface.

Figure 9 is a plot of the temperature differences at the lowest model level, $\sim 992$ $\mathrm{hPa}$, for January. The differences are small, with very limited regions judged significant. This is consistent with the findings of W95 who also saw a limited impact at the surface. However, as pointed out by W95, there are local regions where the changes are significant. This does indicate the possibility of regional climate change, in the context of an approximately constant globally average surface temperature field. This result is consistent with the IPCC (1995) assessment that the effects of the ozone changes alone have in minor impact on climate.

Figure 10 shows the differences in the $500 \mathrm{hPa}$ pressure velocity, dp/dt, for January, March, July and October. Due to the large variance of this field there are only 
small regions deemed significant. Nonetheless, there are patterns of vertical motion consistent with the altered planetary wave structure shown by the zonal wind. The lack of significant regions make a detailed examination of this field less fruitful, but they are presented to indicate the possible impact on the weather distributions in the two simulations.

\section{Conclusions}

The NCAR CCM3 was integrated for six years using two different climatological ozone data sets. Both sets described the 12 month seasonal cycle and were in the form of pressure, latitude cross sections. The two data sets were the ozone data provided in the CCM3 distribution which are data described by Dutsch (1978) and data prepared at SUNYA described by Wang et al. (1995). The SUNYA data reflect the recent ozone depletions in the polar regions. These and other differences are described in the first section of this report. All other aspects of the two six year simulation were identical.

The means and variance of the two six year runs were computed for the 12 months of the year. From these data a simple t-test was used to delineate regions where the differences between the monthly means might be significant. Plots of the differences along with the significance levels indicated the following:

(1) The differences in temperature were for the most part confined to the upper most layers of the model, The zonally averaged temperature differences were consistent with what would be expected given the ozone difference patterns. As shown by Wang et al. (1995) the impact of a new ozone climatology is generally small at the lowest levels, but the impact on the upper levels can be significant.

(2) The ozone depleted regions in the spring about the poles evince a fairly deep (down to $300 \mathrm{hPa}$ ), area of large temperature differences.

(3) Longitude, latitude plots of the zonal wind and temperature differences show that the patterns are markedly zonally asymmetric. The two simulations indicate that the standing waves and thus jet maxima distribution are altered by the new ozone specification. The largest changes are in the Northern Hemisphere in winter.

The zonally asymmetric response to the zonally symmetric ozone prescription might indicate that some caution is warranted in prescribing a three dimensional ozone set. Such a specification could possibly have a substantial impact on the stationary wave pattern and the thus the model climate. As recommended by Wang et 
al. (1995) the GCM's might well need to include an interactive chemical model in order that the ozone distribution can be consistently specified. A longitudinally varying specified ozone might be so inconsistent with the model's stationary wave pattern that the simulation may be compromised in many aspects.

Acknowledgments. The Community Climate Model (CCM), version CCM3, was developed by the Climate and Global Dynamics Division (CGD) Climate Modeling Section (CMS) of the National Center for Atmospheric Research (NCAR), which is operated by the University Corporation for Atmospheric Research (UCAR) and sponsored by the National Science Foundation (NSF). This work was performed under the auspices of the Department of Energy Environmental Sciences Division by the Lawrence Livermore National Laboratory under contract W-7405-ENG-48. 


\section{References}

Dutsch, H. V., 1978: Vertical ozone distribution on a global scale. Pure Appl. Geophys., 116, 511-529.

IPCC, 1995: Climate Change 1995: The Science of Climate Change, J. T. Houghton, L.G. Meira Filho, B. A. Callander, N. Harris, A. Kattenberg and K. Maskell (eds.). Cambridge University Press, Cambridge, UK.

Logan, J. A., 1985: Tropospheric ozone: Seasonal behaviour, trends, and anthropogenic influences. J. Geophys. Res., 90, 10463-10482.

McClatchey, R. A., W. Fenn, J. E. A. Selby, F. E. Volz, and J. S. Garin, 1971: Optical properties of the atmosphere. AFGL-71-0279, Air Force Cambridge Research Laboratories, $85 \mathrm{pp}$.

Molnar, G. I., M-K. W. Ko, S. Zhou and N. D. Sze, 1994: Climate consequences of observed ozone loss in the 1980s: Relevance to the greenhouse problem. J. Geophys. Res., 99, 25755-25760.

Wang, W.-C., Liang, X.-Z. Liang, M. P. Dudek, D. Pollard, S. L. Thompson, 1995: Atmospheric ozone as a climate gas. Atmospheric Research, 37, 247-256.

Spivakovsky, C. M., R. Yevich, J. A. Logan, S. C. Wofsy, and M. B. McElroy, 1990: Tropospheric $\mathrm{OH}$ in a three dimensional chemical tracer model. An assessment based on observations of $\mathrm{CH}_{3} \mathrm{CCL}_{3}$. J. Geophys. Res., 95, 18441-18471. 


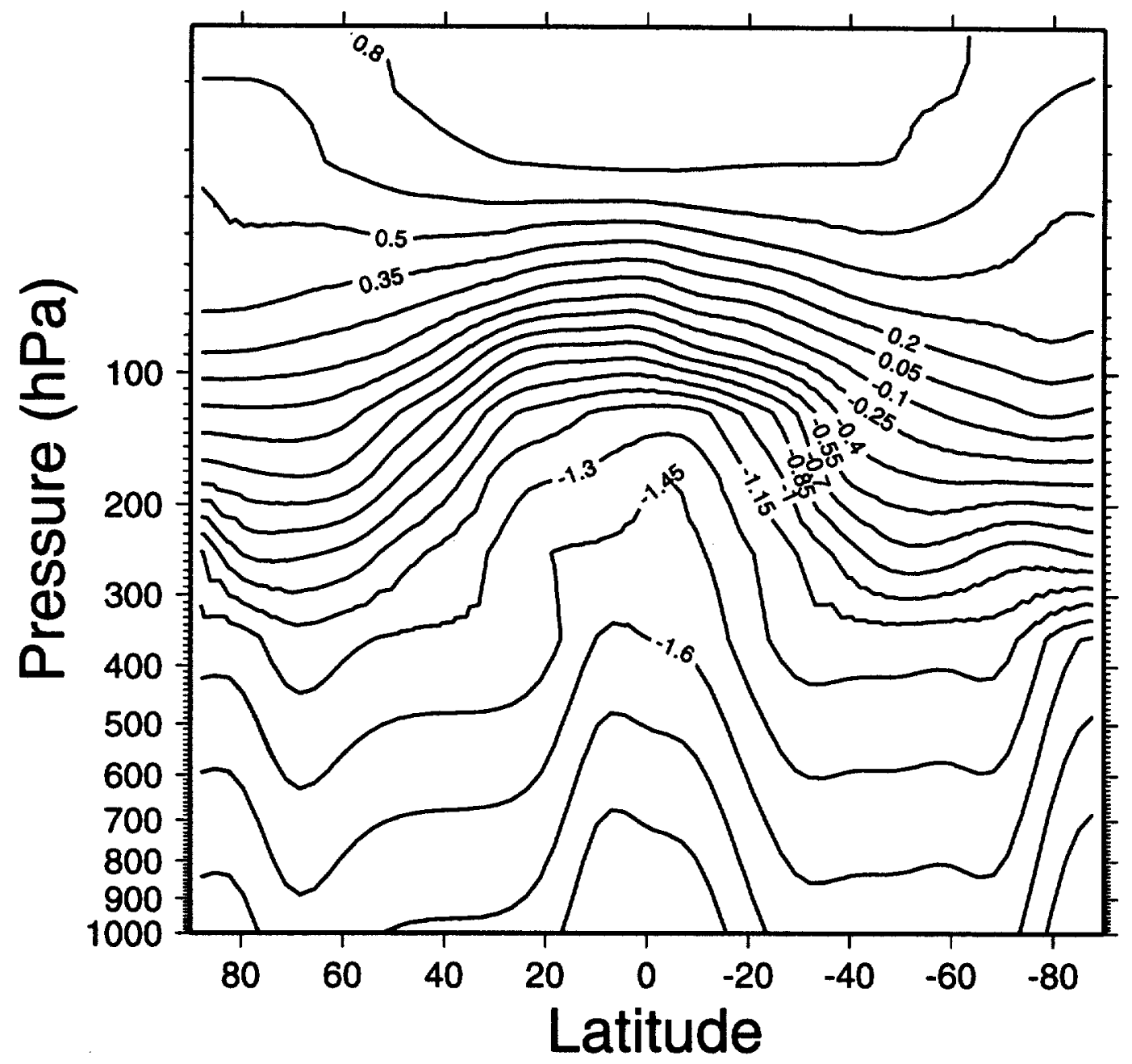

Figure 1. (a) A latitude pressure cross-section of the ozone distribution for the CCM3 ozone data set for October. In order to be able to present the entire depth of the atmosphere on a single diagram the logarithm (base 10) is taken of the original data that was in units of parts per million by volume(pp$\mathrm{mv})$. It is this log data that is plotted on the figure. 
b

SUNYA_october

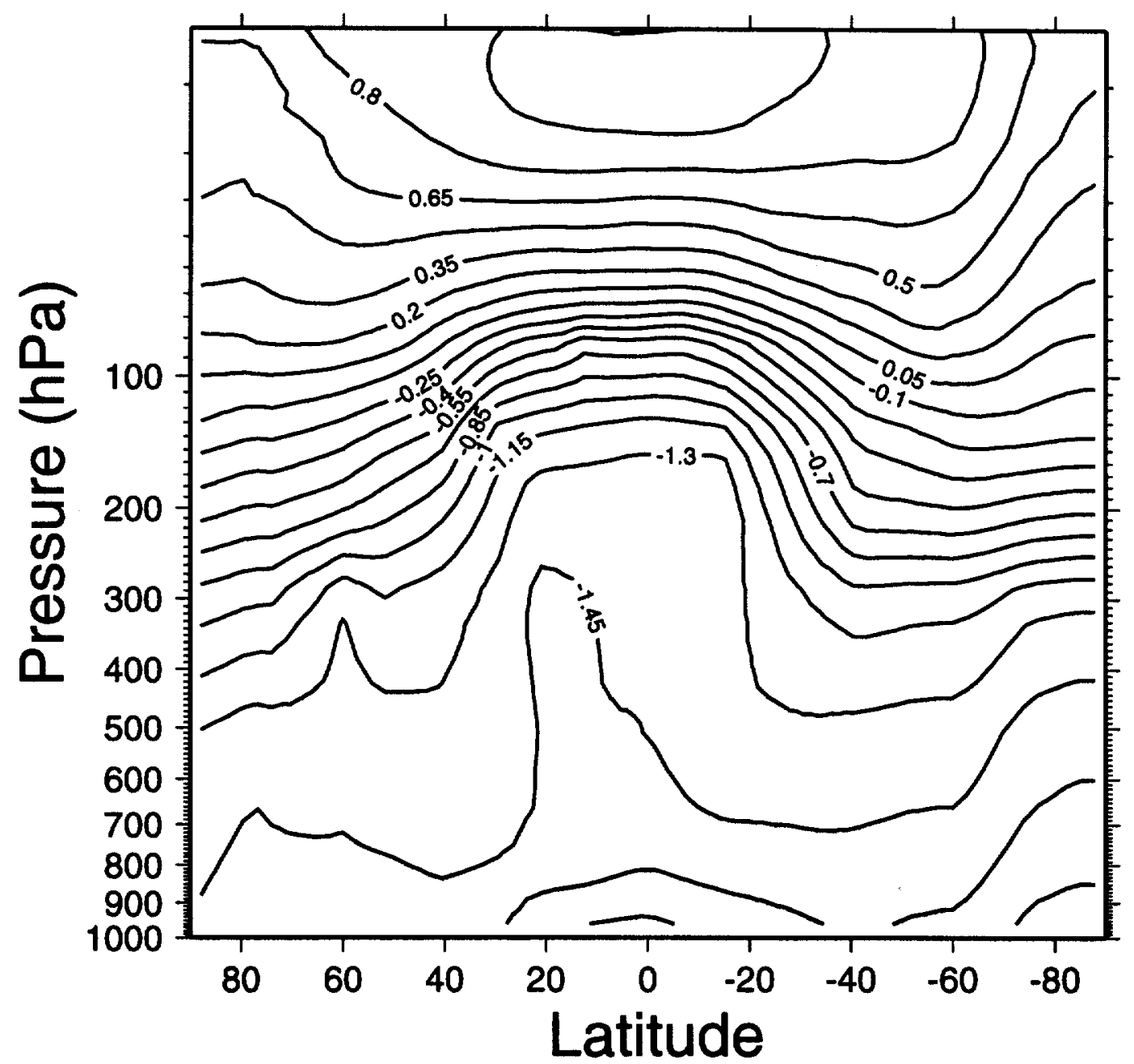

Figure 1. (b) As in (a) except for the SUNYA zonally symmetric data. 

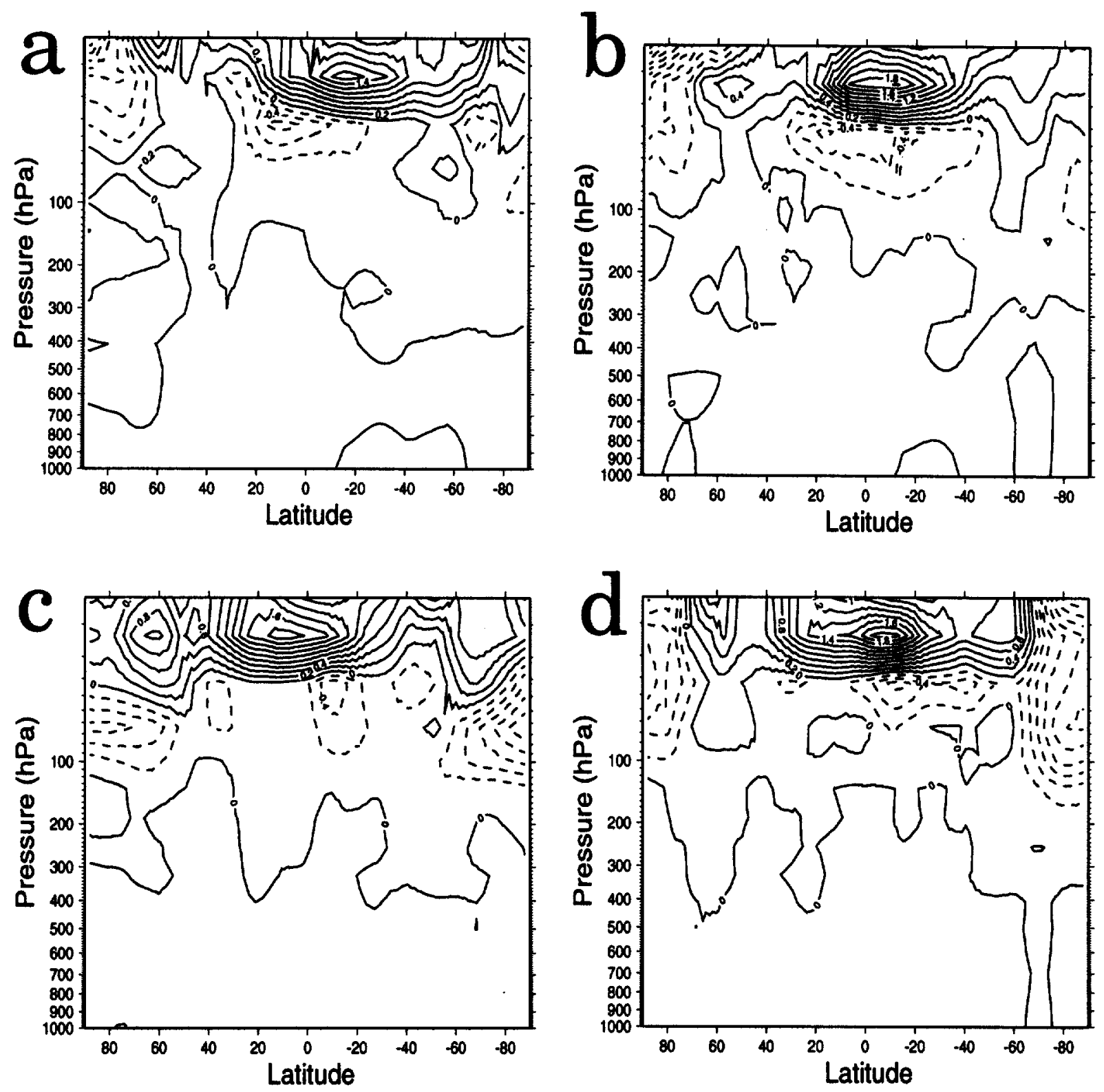

Figure 2. (a) A latitude pressure cross-section of the difference in ozone distribution between the CCM3 and SUNYA data sets in January on the 18 levels of the CCM3 model. Units are parts per million by volume(ppmv). The contour interval in $0.2 \mathrm{ppmv}$. The solid lines indicate positive values, CCM3 < SU. NYA. The dashed lines negative values.

(b) As in (a) except for March.

(c) As in (a) except for July.

(d) As in (a) except for October. 

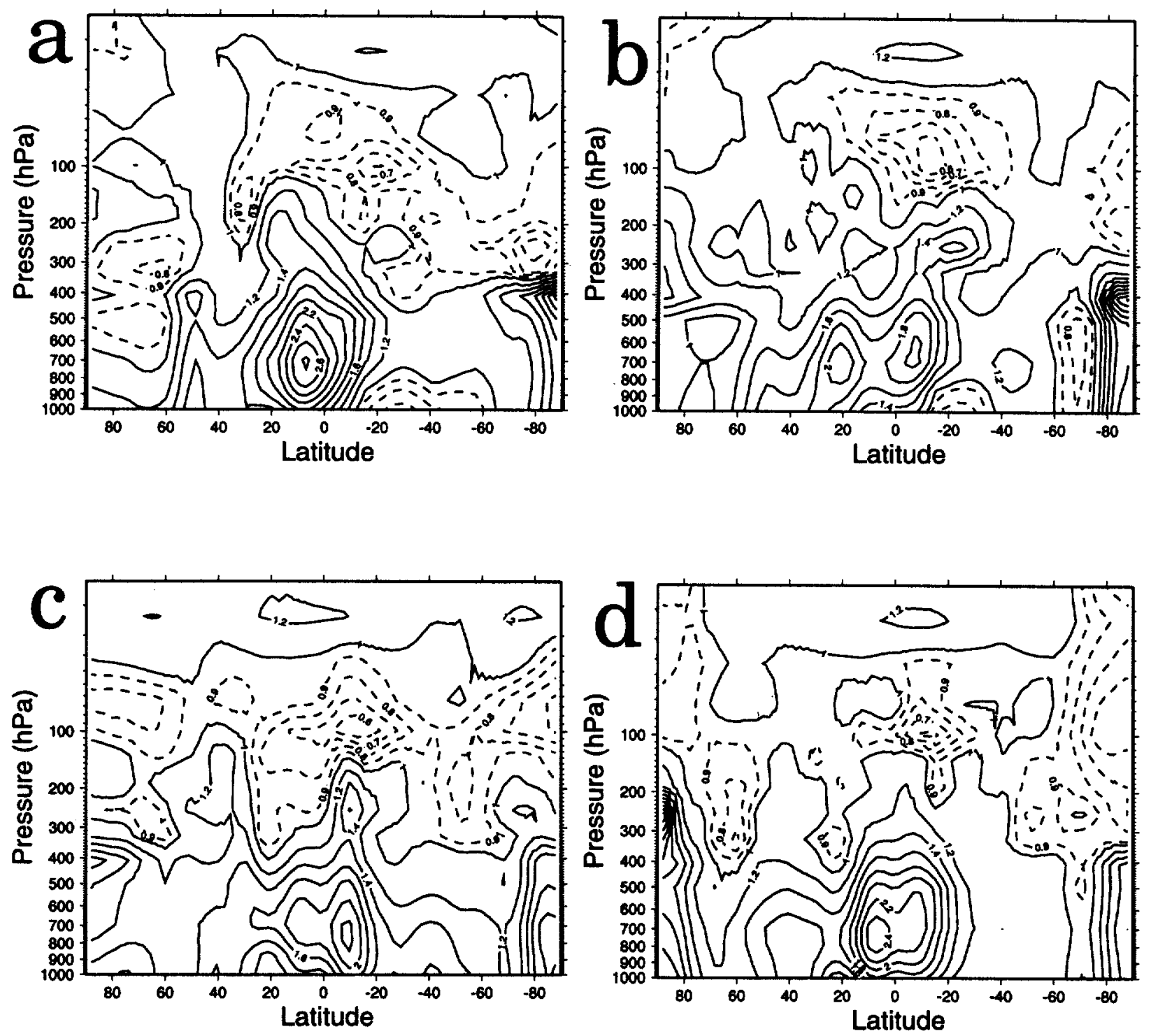

Figure 3. (a) A latitude pressure cross-section of the ratio of the CCM3 and SUNYA ozone distributions in January on the 18 levels of the CCM3 model. The contour interval in 0.2 . The solid lines indicate values greater than 1.0, CCM3 < SUNYA. The dashed lines indicate values less than 1.0

(b) As in (a) except for March.

(c) As in (a) except for July.

(d) As in (a) except for October. 

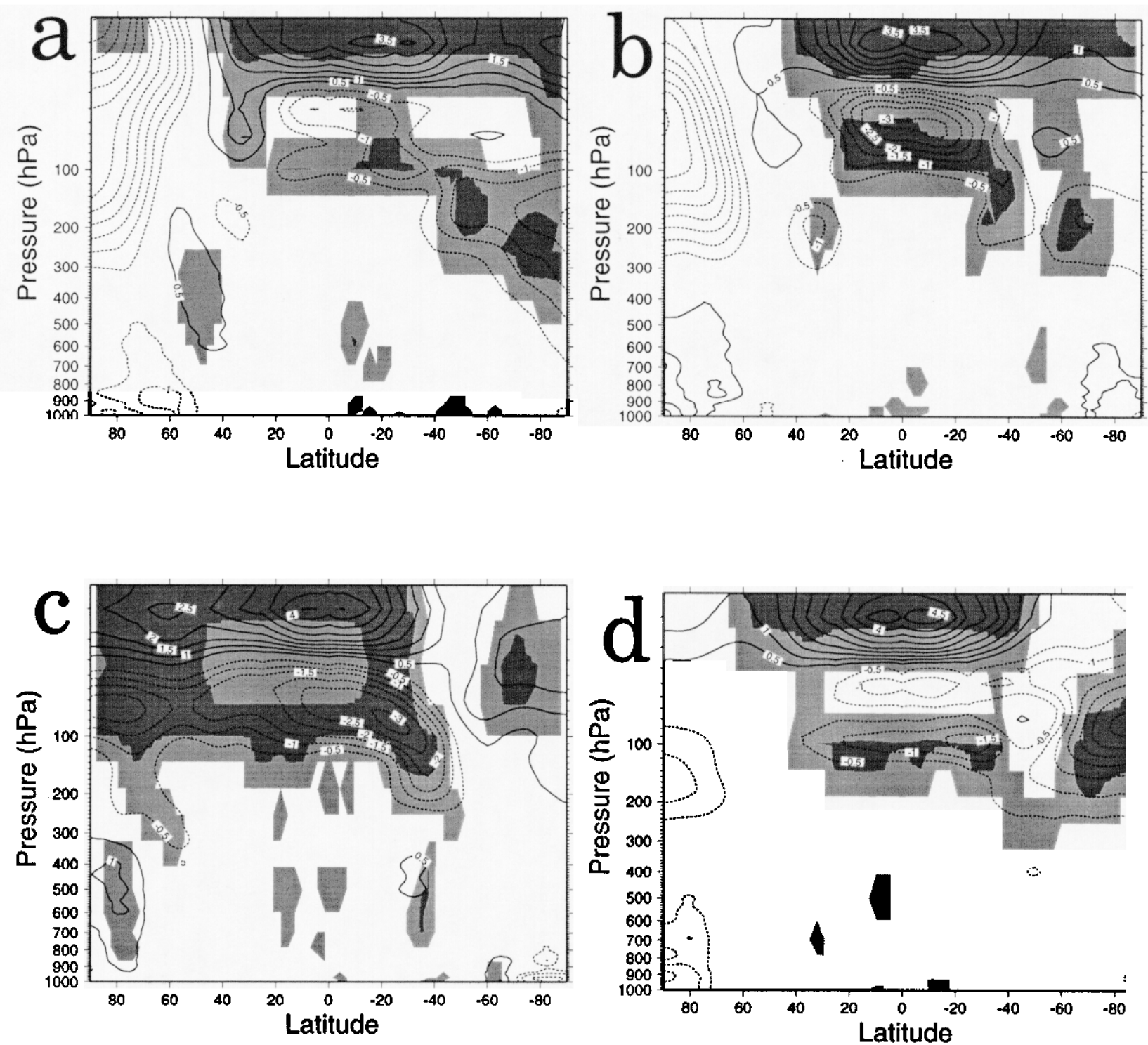

Figure 4. (a) A latitude pressure cross-section of the mean temperature differences between the CCM3 integrations using the CCM3 and SUNYA ozone data sets. The contour interval is $0.5 \mathrm{C}$. The solid lines indicate positive values, the dashed lines negative values. The zero contour is not drawn. The light and dark shading on the plots are the regions judged to be significantly different based on the local t-test at the $5 \%$ and $1 \%$ levels, respectively.

(b) As in (a) except for March.

(c) As in (a) except for July.

(d) As in (a) except for October. 

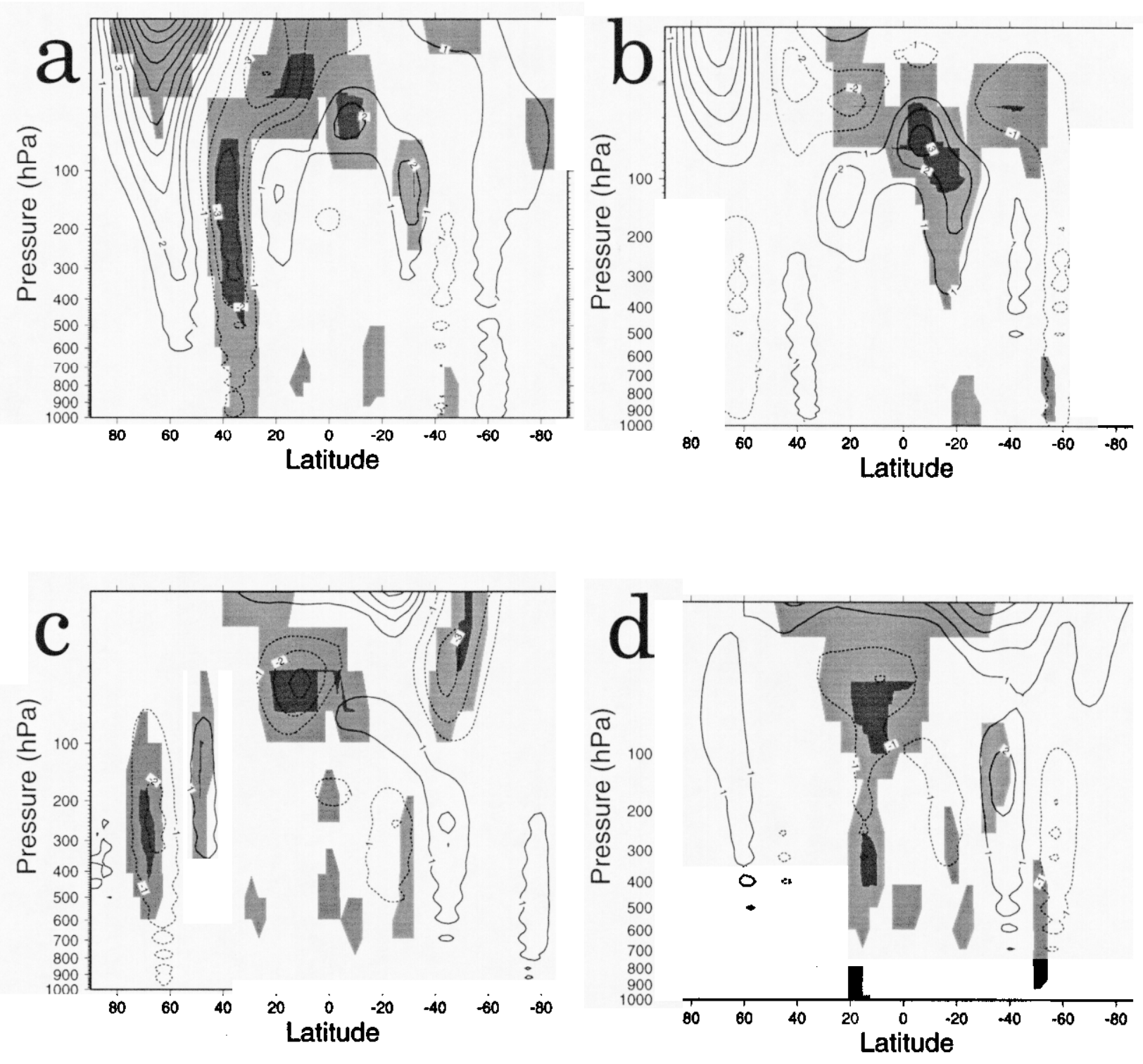

Figure 5. (a) A latitude pressure cross-section of the mean zonal wind differences between the CCM3 integrations using the CCM3 and SUNYA ozone data sets. The contour interval is $1.0 \mathrm{~m} / \mathrm{s}$. The solid lines indicate positive values, the dashed lines negative values. The zero contour is not drawn. The light and dark shading on the plots are the regions judged to be significantly different based on the local t-test at the $5 \%$ and $1 \%$ levels, respectively.

(b) As in (a) except for March.

(c) As in (a) except for July.

(d) As in (a) except for October. 

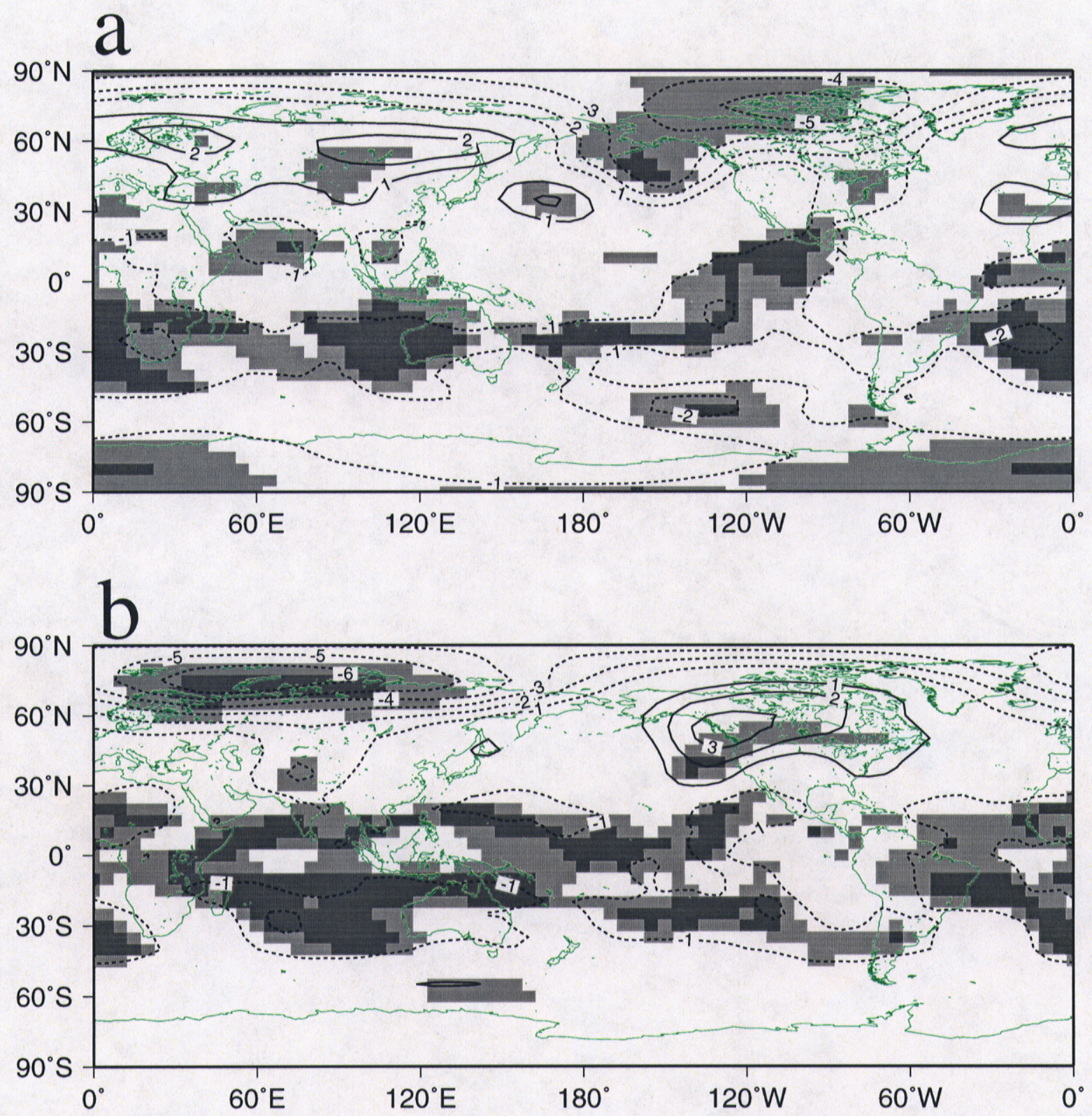

Figure 6. (a) The mean temperature differences between the CCM3 integrations using the CCM3 and SUNYA ozone data sets at the $100 \mathrm{hPa}$ level. The contour interval is $1.0 \mathrm{C}$. The solid lines indicate positive values, the dashed lines negative values. The zero contour is not drawn. The light and dark shading on the plots are the regions judged to be significantly different based on the local t-test at the $5 \%$ and $1 \%$ levels, respectively.

(b) As in (a) except for March. 

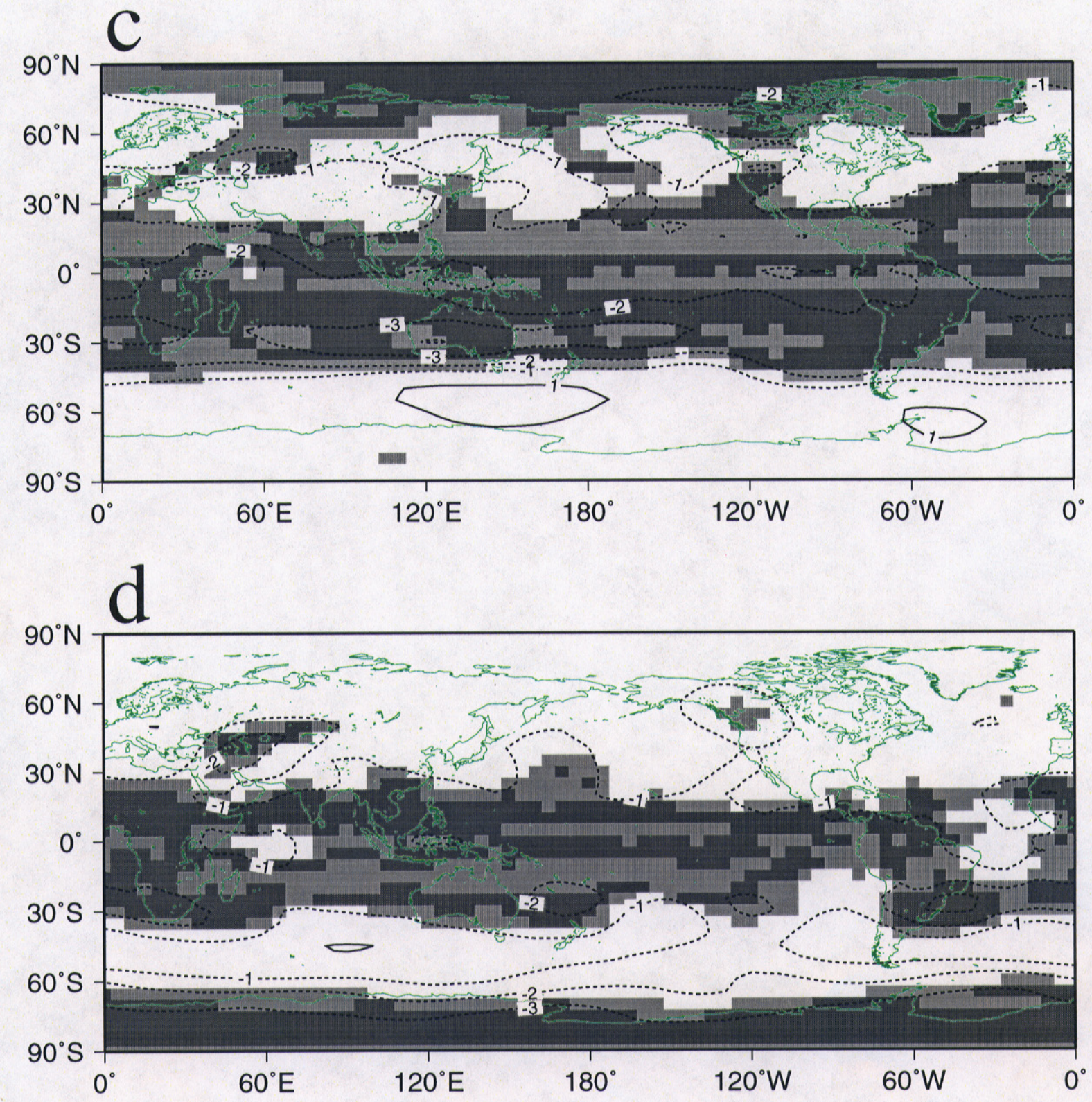

Figure 6(c) As in (a) except for July.

(d) As in (a) except for October. 

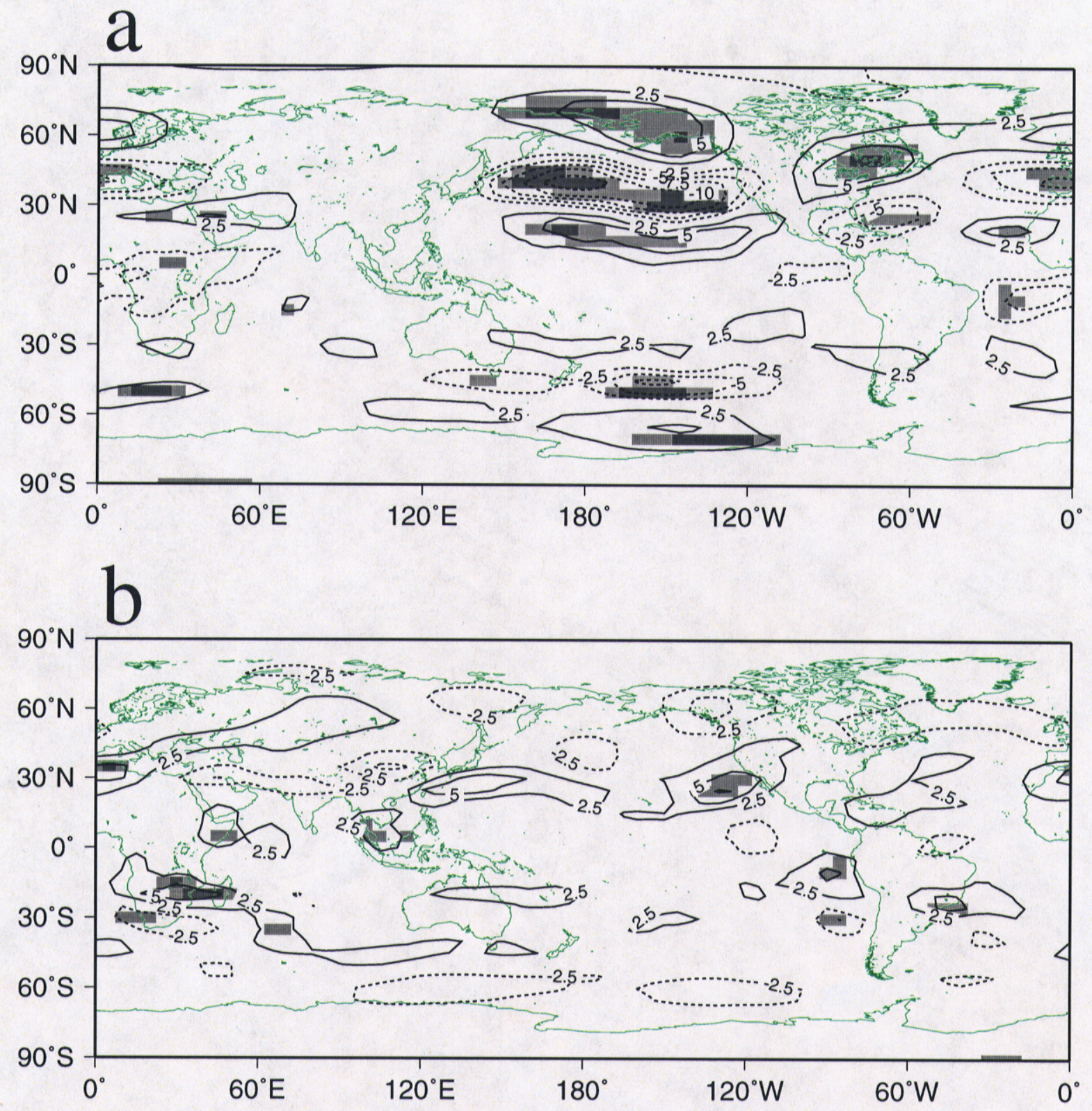

Figure 7. (a) The mean zonal wind differences between the CCM3 integrations using the CCM3 and SUNYA ozone data sets at the $200 \mathrm{hPa}$ level. The contour interval is $2.5 \mathrm{~m} / \mathrm{s}$. The solid lines indicate positive values, the dashed lines negative values. The zero contour is not drawn. The light and dark shading on the plots are the regions judged to be significantly different based on the local t-test at the $5 \%$ and $1 \%$ levels, respectively.

(b) As in (a) except for March. 

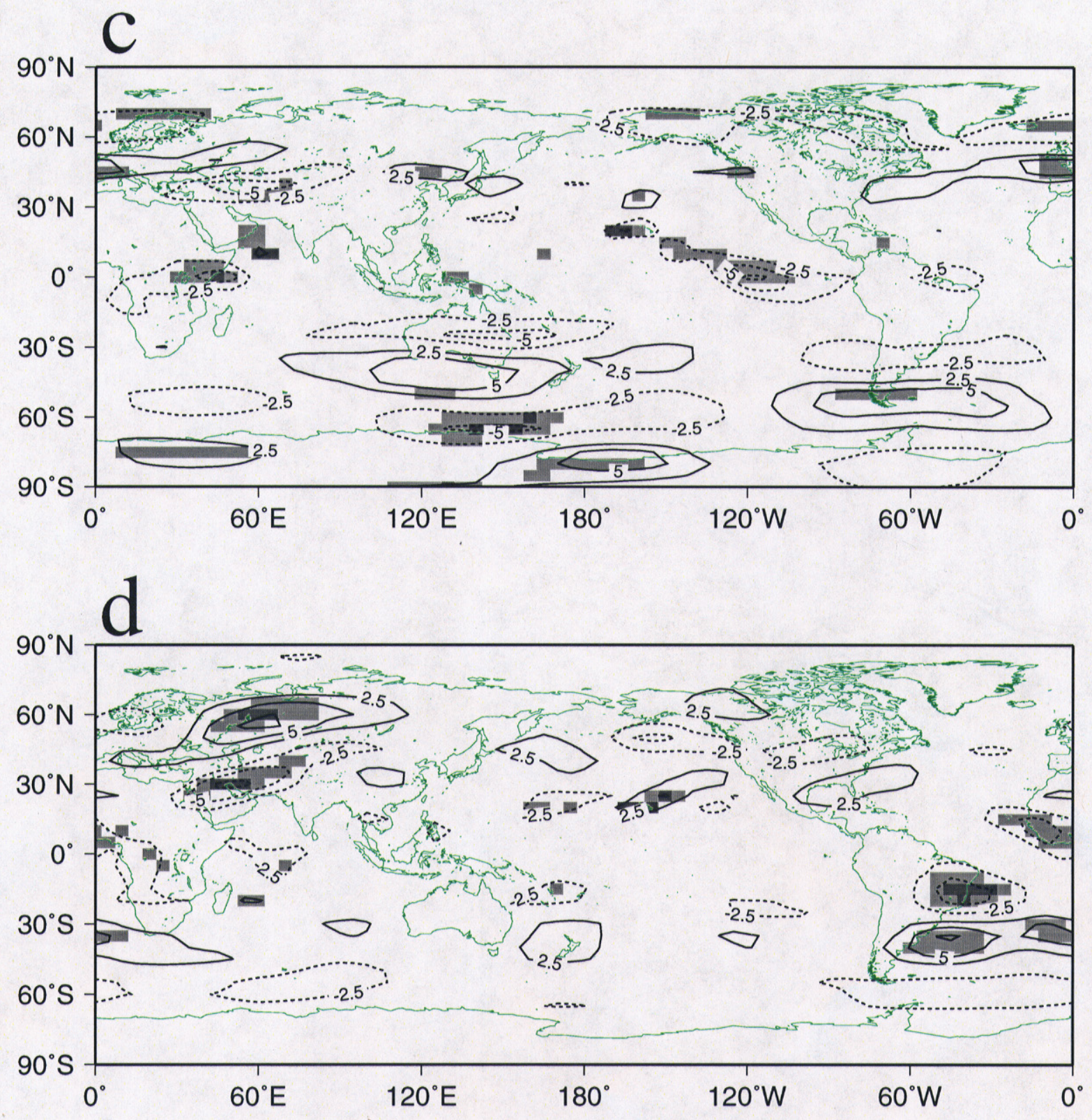

Figure 7(c). As in (a) except for July. (d) As in (a) except for October. 


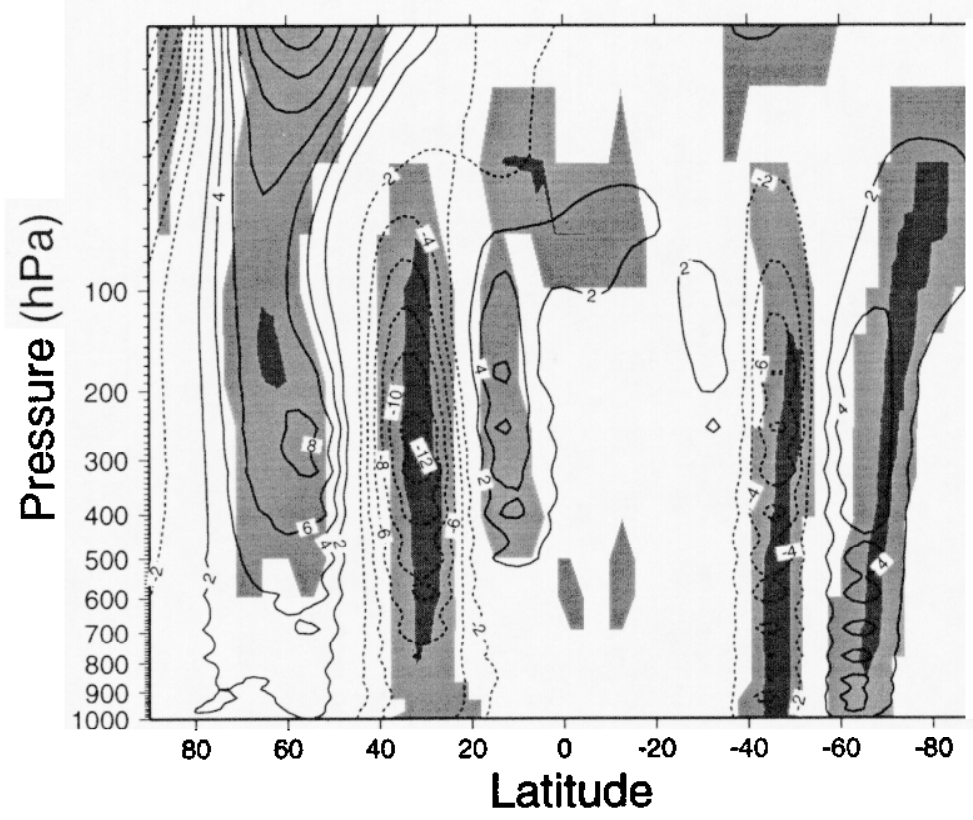

Figure 8. (a) A latitude pressure cross-section of the mean zonal wind differences between the CCM3 integrations using the CCM3 and SUNYA ozone data sets for January at 150W. The contour interval is $2.0 \mathrm{~m} / \mathrm{s}$. The solid lines indicate positive values, the dashed lines negative values. The zero contour is not drawn. The light and dark shading on the plots are the regions judged to be significantly different based on the local t-test at the $5 \%$ and $1 \%$ levels, respectively. 


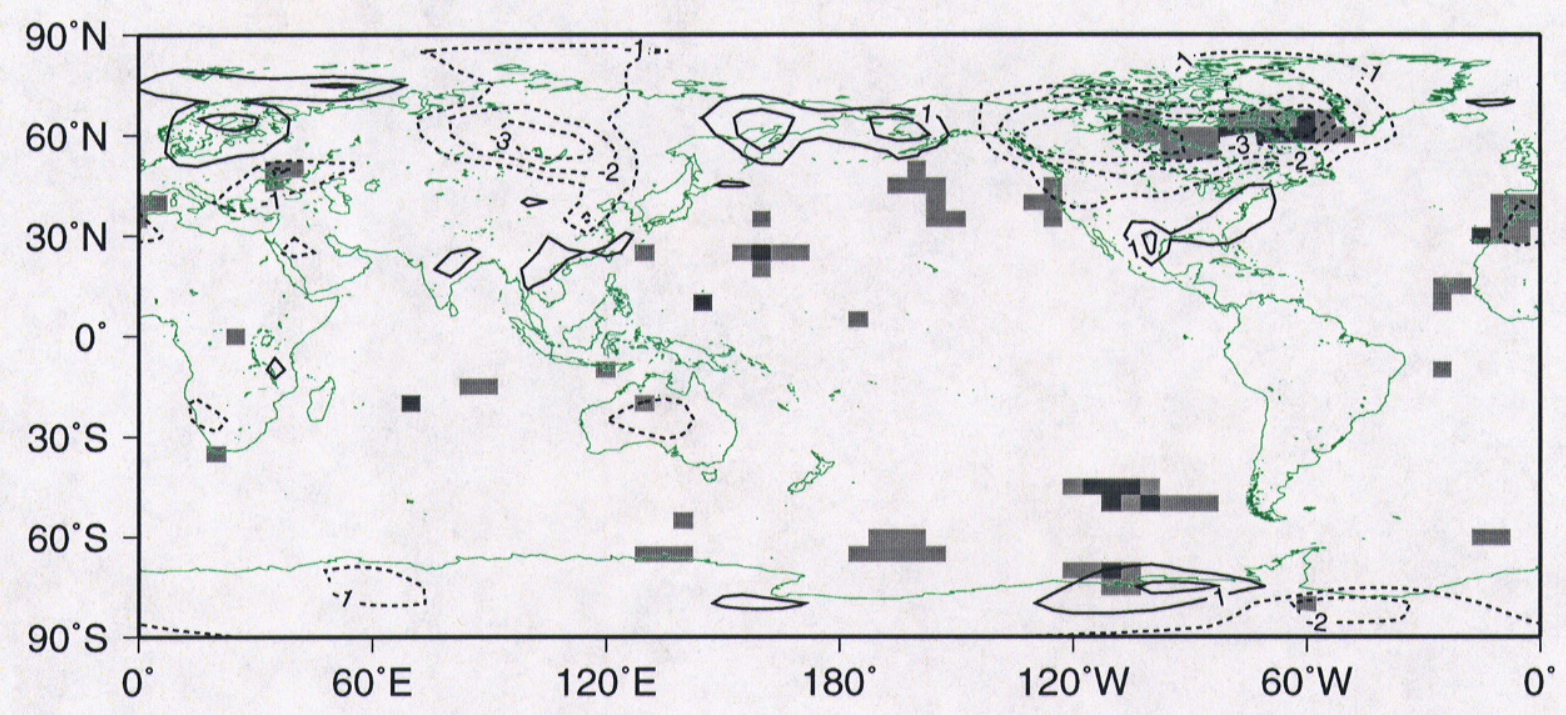

Figure 9. (a) The mean temperature differences between the CCM3 integrations using the CCM3 and SUNYA ozone data sets at the $992 \mathrm{hPa}$ level. The contour interval is $1.0 \mathrm{C}$. The solid lines indicate positive values, the dashed lines negative values. The zero contour is not drawn. The light and dark shading on the plots are the regions judged to be significantly different based on the local t-test at the 5\% and $1 \%$ levels, respectively. 


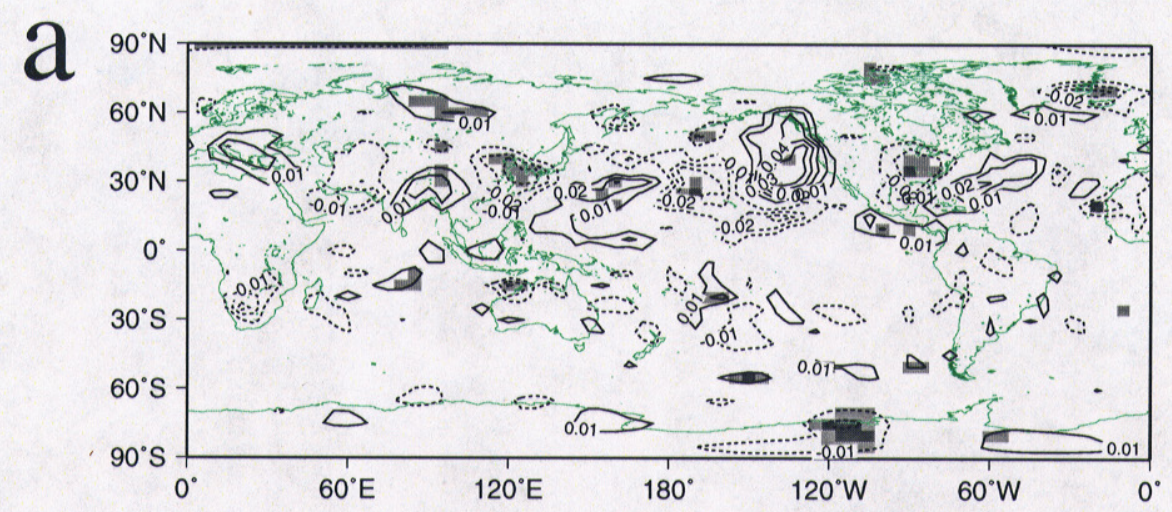

b
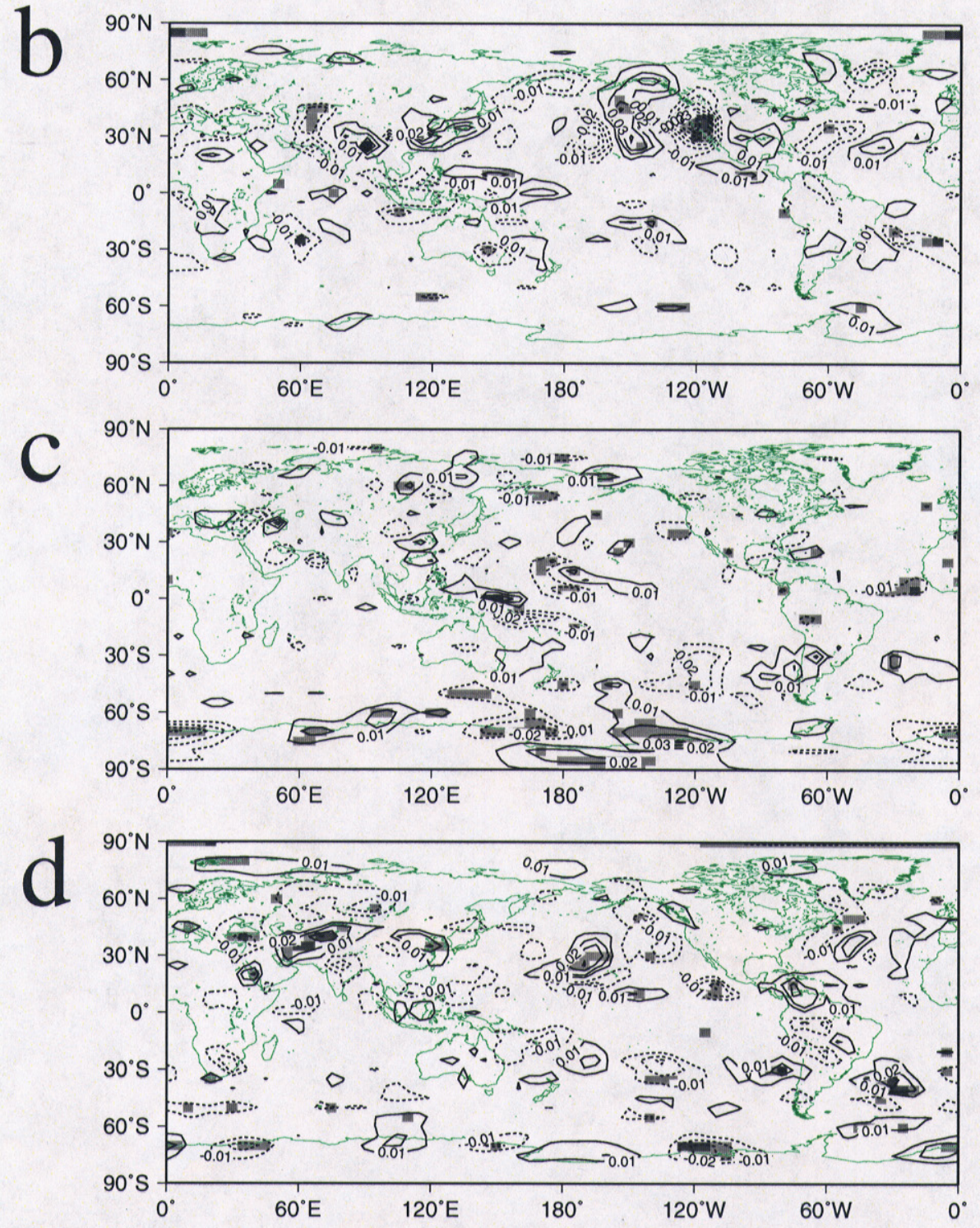

Figure 10. (a) The mean pressure vertical velocity (dp/dt) differences between the CCM3 integrations using the CCM3 and SUNYA ozone data sets at the $500 \mathrm{hPa}$ level. The contour interval is $0.0001 \mathrm{pa} /$ $\mathrm{s}$. The solid lines indicate positive values, the dashed lines negative values. The zero contour is not drawn. The light and dark shading on the plots are the regions judged to be significantly different based on the local t-test at the 5\% and 1\% levels, respectively. (b) As in (a) except for March. (c) As in (a) except for July. (d) As in (a) except for October. 
Figure 1. (a) A latitude pressure cross-section of the ozone distribution for the CCM3 ozone data set for October. In order to be able to present the entire depth of the atmosphere on a single diagram the logarithm (base 10) is taken of the original data that was in units of parts per million by volume(pp$\mathrm{mv}$ ). It is this log data that is plotted on the figure.

(b) As in (a) except for the SUNYA zonally symmetric data.

Figure 2. (a) A latitude pressure cross-section of the difference in ozone distribution between the CCM3 and SUNYA data sets in January on the 18 levels of the CCM3 model. Units are parts per million by volume(ppmv). The contour interval in $0.2 \mathrm{ppmv}$. The solid lines indicate positive values, CCM3 < SUNYA. The dashed lines negative values.

(b) As in (a) except for March.

(c) As in (a) except for July.

(d) As in (a) except for October.

Figure 3. (a) A latitude pressure cross-section of the ratio of the CCM3 and SUNYA ozone distributions in January on the 18 levels of the CCM3 model. The contour interval in 0.2 . The solid lines indicate values greater than 1.0, CCM3 < SUNYA. The dashed lines indicate values less than 1.0

(b) As in (a) except for March.

(c) As in (a) except for July.

(d) As in (a) except for October.

Figure 4. (a) A latitude pressure cross-section of the mean temperature differences between the CCM3 integrations using the CCM3 and SUNYA ozone data sets. The contour interval is $0.5 \mathrm{C}$. The solid lines indicate positive values, the dashed lines negative values. The zero contour is not drawn. The light and dark shading on the plots are the regions judged to be significantly different based on the local t-test at the $5 \%$ and $1 \%$ levels, respectively.

(b) As in (a) except for March.

(c) As in (a) except for July.

(d) As in (a) except for October.

Figure 5. (a) A latitude pressure cross-section of the mean zonal wind differences between the CCM3 integrations using the CCM3 and SUNYA ozone data sets. The contour interval is $1.0 \mathrm{~m} / \mathrm{s}$. The solid lines indicate positive values, the dashed lines negative values. The zero contour is not drawn. The light and dark shading on the plots are the regions judged to be significantly different based on the local t-test at the $5 \%$ and $1 \%$ levels, respectively.

(b) As in (a) except for March.

(c) As in (a) except for July. 
(d) As in (a) except for October.

Figure 6. (a) The mean temperature differences between the CCM3 integrations using the CCM3 and SUNYA ozone data sets at the $100 \mathrm{hPa}$ level. The contour interval is $1.0 \mathrm{C}$. The solid lines indicate positive values, the dashed lines negative values. The zero contour is not drawn. The light and dark shading on the plots are the regions judged to be significantly different based on the local t-test at the $5 \%$ and $1 \%$ levels, respectively.

(b) As in (a) except for March.

(c) As in (a) except for July.

(d) As in (a) except for October.

Figure 7. (a) The mean zonal wind differences between the CCM3 integrations using the CCM3 and SUNYA ozone data sets at the $200 \mathrm{hPa}$ level. The contour interval is $2.5 \mathrm{~m} / \mathrm{s}$. The solid lines indicate positive values, the dashed lines negative values. The zero contour is not drawn. The light and dark shading on the plots are the regions judged to be significantly different based on the local t-test at the $5 \%$ and $1 \%$ levels, respectively.

(b) As in (a) except for March.

(c) As in (a) except for July.

(d) As in (a) except for October.

Figure 8. (a) A latitude pressure cross-section of the mean zonal wind differences between the CCM3 integrations using the CCM3 and SUNYA ozone data sets for January at 150W. The contour interval is $2.0 \mathrm{~m} / \mathrm{s}$. The solid lines indicate positive values, the dashed lines negative values. The zero contour is not drawn. The light and dark shading on the plots are the regions judged to be significantly different based on the local t-test at the $5 \%$ and $1 \%$ levels, respectively.

Figure 9. (a) The mean temperature differences between the CCM3 integrations using the CCM3 and SUNYA ozone data sets at the $992 \mathrm{hPa}$ level. The contour interval is $1.0 \mathrm{C}$. The solid lines indicate positive values, the dashed lines negative values. The zero contour is not drawn. The light and dark shading on the plots are the regions judged to be significantly different based on the local t-test at the 5\% and $1 \%$ levels, respectively.

Figure 10. (a) The mean pressure vertical velocity (dp/dt) differences between the CCM3 integrations using the CCM3 and SUNYA ozone data sets at the $500 \mathrm{hPa}$ level. The contour interval is $0.0001 \mathrm{pa}$ s. The solid lines indicate positive values, the dashed lines negative values. The zero contour is not drawn. The light and dark shading on the plots are the regions judged to be significantly different based on the local t-test at the $5 \%$ and $1 \%$ levels, respectively.

(b) As in (a) except for March. 
(c) As in (a) except for July.

(d) As in (a) except for October. 


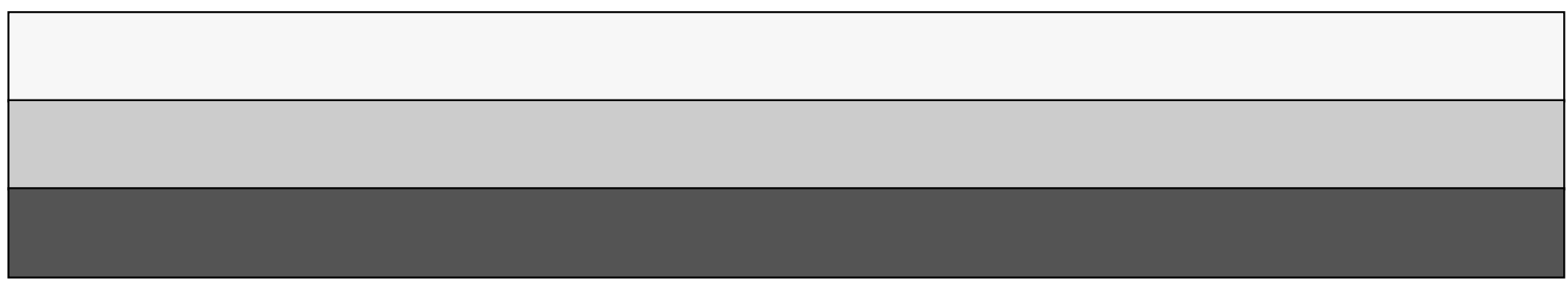

